shopping, housework and children, as well as the presence on leave of husband or son. There must also be considered the less obvious but important conditions that affect the body and the mind of the individual worker; for example, boredom, lack of understanding of the value of his work, anxiety, illhealth. As much care should be taken of the health of the industrial worker as is taken of the health of the men and women in the Fighting Forces.

The accumulated effects of war-time conditions have caused in many workers a state vaguely labelled industrial fatigue, of which one expression is in absenteeism.

During a war it is impossible to avoid making heavy demands on people's energy ; but it should have been possible, if adequate use had been made of the available knowledge, to have prevented some of the worst effects. Unfortunately, for diagnostic purposes the effects of fatigue and those of boredom are similar, namely, lowered output, inferior quality of work, increase of accidents, discontent, and some physical symptoms of ill-health. Fatigue and boredom also affect one's attitude to the work and to the War. The over-tired or very bored worker becomes despondent or indifferent, and tends to lose his sense of proportion in regard to himself and his surroundings, as well as to the course of the War. The remedies are not really difficult to deduce or to make effective.

The weekly hours should not exceed 60 for men and 55 for women, and even these are too high for certain classes of work. The week-end break is important. There should be adequate rest pauses within each spell of work. Attention should be given to the design and speed of machines, and to the selection and training of people for the jobs they are best fitted to undertake. Good working conditions including canteens, and rest and recreation rooms, help to decrease fatigue and boredom, and music is a very popular antidote.

The pamphlet is most attractively printed, produced and illustrated.

\section{NATURAL HISTORY OF THE MINNOW}

$\mathrm{M}$ ISS WINIFRED FROST has done good work on the biology and natural history of the minnow Phoxinus phoxinus (J. Animal Ecol., 12, No. 2 ; Nov. 1943). Taking Lake Windermere and one of its affluent streams, the River Brathay, as headquarters, the minnow has been studied in detail for two years. The investigation deals with its habits, growth, food and reproduction. Minnows are active and pelagic in both lake and stream from April until October, and migrate into deeper water where they are relatively passive and hidden under stones from November to March. They breed from May until July, sexual maturity in a few being reached at the end of the first year : the majority of those in their second year and all older fish are mature.

Length frequency curves supported by scale examination indicate that there are certainly three-year classes, and suggest the possibility of a fourth. The feeding habits have been studied intensively and it is found that in the lake, although a variety of feod is taken, planktonic Crustacea, particularly Cladocera, form the chief food and these are also much eaten by the other fish. The supply of these organisms is, however, so large that it seems unlikely that the minnow is a serious competitor for food in this com- munity, especially because of its inshore habits. In the river, Algæ are eaten, a much larger proportion of insect larvæ and less Cladocera and copepods. Much of the food here is similar to that of the young brown trout, and competition is likely. As to enemies, there are many, for the minnow is eaten by a few trout and many perch but not much by the pike. Eels also eat it and it forms part of the diet of the brown trout.

In Windermere and similar large lakes the conclusion is that it is unlikely that the minnow is a serious competitor for food, and it is of itself an appreciable source of food for larger fish. In running water inhabited primarily by salmon and trout the possibility of serious competition is great. So far as fishery conservation is concerned it is concluded that in general, provided the fish population is balanced with active predators to keep their numbers in check, it may be said that minnows are not inimical to a fishery. If, however, the balance is disturbed in favour of fish such as salmon and trout to the exclusion of the more active predatory fish, the minnow may multiply and become a menace.

\section{JUTE STUDIES}

$\mathrm{R}^{\mathrm{B}}$ ECENTLY there have been several Indian publications upon the anatomy of jute (Corchorus) with special reference to the fibre production and development. Such studies are to be welcomed as affording a basis for the practical improvement of varieties and for modification of extraction and preparation methods.

An earlier paper by Prof. B. C. Kundu (J. Indian Bot. Soc., 21, 93 ; 1942) has been followed by Agricultural Research Memoir No. 1 from the Indian Central Jute Committee. This confirms the work of Kundu in the main particulars, though the authors, S. S. Ghosh, K. R. Rao and J. S. Patel do not agree that the original protophloem of jute is secondary in origin. Discrepancies here may be associated with the age of the shoot apex examined; certainly Kundu's figures of the early procambial strands are striking in their demonstration of the early growth being entirely by longitudinal divisions, though it may not necessarily be solely with radial seriation as in the case of cambial activity.

In $C$. capsularis these authors record the presence of a distinct periderm, not seen by Kundu, much of whose material was grown under greenhouse conditions in England; the authors note how this periderm, as also the free development of adventitious roots at the base of plants frequently flooded during growth, may prove a deleterious influence upon the ready separation of the fibre during retting.

As Agricultural Research Memoir No. 2, Messrs. J. S. Patel and S. S. Ghosh have published a preliminary study of the anatomy of retted jute. These studies have shown how progressive the isolation of the fibre strands may be; thus they may be free in the top portion of the stem in five-six days, in the middle of the stem in nine-twelve days and at the base only after fifteen-twenty days. Heavily lignified fibres resist retting, while near nodes, injuries, etc., retting is usually delayed (this was exemplified, in the case of nodes, in some photographs communicated by J. H. Priestley to the late Dr. S. G. Barker, J. Textile Inst., $30,273 ; 1939)$. These retting studies contain some preliminary notes on retting organisms; but these need extension by isolation and culture of the organisms by the usual methods. 